\title{
Dietary grape seed tannin extract supplementation stimulated testis development, changed fatty acid profiles and increased antioxidant capacity in testis in Hu lambs in pre-puberty
}

\section{Wanhong Li ( $\square$ limh@lzu.edu.cn )}

Lanzhou University https://orcid.org/0000-0002-2155-6863

\section{Rongyu Yao}

Lanzhou University College of Pastoral Agriculture Science and Technology

\section{Lixia Xie}

Wuwei Occupational College

Jiamei Liu

Lanzhou University College of Pastoral Agriculture Science and Technology

\section{Xiuxiu Weng}

Lanzhou University College of Pastoral Agriculture Science and Technology

\section{Xiangpeng Yue}

Lanzhou University College of Pastoral Agriculture Science and Technology

\section{Fadi Li}

Lanzhou University College of Pastoral Agriculture Science and Technology

\section{Research}

Keywords: Testis, Tannin, Fatty acids, Antioxidant capacity, SOD

Posted Date: March 3rd, 2021

DOI: https://doi.org/10.21203/rs.3.rs-261964/v1

License: (c) (1) This work is licensed under a Creative Commons Attribution 4.0 International License.

Read Full License

Version of Record: A version of this preprint was published at Theriogenology on June 1st, 2021. See the published version at https://doi.org/10.1016/j.theriogenology.2021.06.015. 


\section{Abstract \\ Background}

Grape seed tannin extract (GPE) that is from wine grape pomace has many effective anti-oxidative effects and is used as a promising natural feed additive in the animal feed industry. In this study, we investigated the effect of GPE as a source of tannin on the antioxidant capacity and testis development in Hu lamb.

\section{Method:}

Twenty-seven 3-month-old ram lambs were randomly assigned to three groups. Within each treatment group, nine lambs were allocated to nine pens (one lamb per pen). The lambs in the control group were fed a control diet without GPE for 61 days from D21 to D80. Group I (TAN1) was fed a $0.36 \%$ GPE diet. Group II (TAN2) was fed a $0.72 \%$ GPE diet. After 81-day feeding trial, all lambs except the heaviest and lightest in each group were humanely slaughtered and investigated.

\section{Results}

Feeding GPE did not affect the body weight, average daily gain, dry matter intake, scrotal circumference and testis index, whereas feeding $0.36 \%$ GPE diet increased testis weight, testis volume, and epididymis weight $(P<0.05)$ compared with the control. Cu-ZnSOD, P450scc, P450arom, FSHR, FADS2, ELOVL2 and PCNA mRNA in TAN1 and TAN2 groups were significantly up-regulated $(P<0.05)$. GPE also markedly increased antioxidant status of testis. Compared with the control group, GPE significantly increased the SOD activity (314.23 $\pm 18.64 \mathrm{U} / \mathrm{mg}$ prot in control, $505.22 \pm 63.47 \mathrm{U} / \mathrm{mg}$ prot in TAN1 and $587.88 \pm 55.94$ $\mathrm{U} / \mathrm{mg}$ prot in TAN2, $P<0.05)$, T-AOC $(98.23 \pm 18.99 \mathrm{U} / \mathrm{g}$ prot in control, $202.15 \pm 34.19 \mathrm{U} / \mathrm{g}$ prot in TAN1 and $189.57 \pm 18.95 \mathrm{U} / \mathrm{g}$ prot in TAN2, $P<0.05)$. GPE also increased NEFAs levels $(158.36 \pm 26.32$ $\mathrm{mmol} / \mathrm{kg}$ prot in control, $205.15 \pm 14.51 \mathrm{mmol} / \mathrm{kg}$ prot in TNA1 and $250.06 \pm 33.82 \mathrm{mmol} / \mathrm{kg}$ prot in TAN2 $P=0.08)$. But, consuming GPE downregulated testicular total cholesterol concentration $(3.89 \pm 0.57$ $\mathrm{mmol} / \mathrm{kg}$ prot in TAN1, $4.21 \pm 1.04 \mathrm{mmol} / \mathrm{kg}$ prot in TAN2 and $7.20 \pm 1.46 \mathrm{mmol} / \mathrm{kg}$ prot, $P=0.09$ ). Consuming $0.72 \%$ GPE also changed fatty acid profiles in testis with increased C15:1, C22:6n3 and total $\mathrm{n}-3$ fatty acids $(P<0.05)$. Therefore, feeding lambs with $0.72 \%$ GPE stimulated testis seminiferous tubule development, increased the number of Sertoli cells ( $10.56 \pm 0.44$ vs. $13.60 \pm 0.42, P<0.05)$, and seminiferous tubule diameter $(146.56 \pm 4.53 \mu \mathrm{m}$ vs. $109.3 \pm 4.56 \mu \mathrm{m}, P<0.05)$.

\section{Conclusion}

All these results suggested that feeding GPE in the early reproductive development stage of lambs upregulated the expression of antioxidative, steroidogenesis, and PUFA metabolism-related genes; 
changed the fatty acids profiles, increased the antioxidant capacity in lamb's testis; and contributed to testis development and spermatogenesis.

\section{Introduction}

Based on data from the international Organization of Vine and Wine, China is the second in a list of vineyard surface area of major vine-growing countries (2019). Wine grape pomace (WGP)is the major byproduct of the red wine industry and consists mainly of stems, skins and seeds. WPG is treated as a waste due to the lack of alternative uses with economic benefits for a long time. Importantly, WGP and it extract have even more effective anti-oxidative effects than vitamin $C$ and Vitamin $E[1,2]$, and thus can be used as a promising natural feed additive in the animal industry. It is estimated that only $3 \%$ of the global WGP is used as animal feed. The low usage of WGP in livestock production is due to its high content of monomeric phenolic compounds, mainly tannin which is associated with reduced digestibility through the inhibition of cellulolytic and proteolytic enzymes[3, 4]. In pursuit of sustainable and economically viable ruminant livestock systems, many farmers are under increasing pressure to maximize the use of available agricultural by-products-based diets for their livestock without compromising the performance. In livestock husbandry, tannin has been studied for it deterrent effects on herbivores, pathogens, parasites, or toxicity[5-7]. Tannin also affected feed utilization and especially protected protein from fermentation including a shift in $\mathrm{N}$ excretion from urine to feces, and reduced ruminate methanogenesis $[8,9]$.

China's lamb production areas are mainly located in the West and Northwest, and are characterized by fragile ecology [10]. The Hexi/Gansu Corridor is one of the main wine producing areas and the lamb production area, suggesting the possible use of WGP in the lamb industry. China highly values ecological and environmental protection. Guided by the conviction that lucid waters and lush mountains are invaluable assets, the country advocates harmonious coexistence between humans and nature, and sticks to the path of green and sustainable development, which includes the requirement of pen-raising for sheep.

However, oxidative stress is induced in lambs raised in pens, which decreases testes weight and spermatogenesis, impairs epididymis sperm quality [11]. Most of previously studies about dietary supplements on testis antioxidant capacity or spermatogenesis were in adult rams[11] Interestingly, grape seed tannin extract (GPE) attenuates oxidative stress, and enhances sperm motility in rats[12]. Thus, the current study aimed to evaluate the effect of GPE on reproduction hormone synthesis, testis development, fatty acid profiles and testis antioxidative in $H u$ ram lambs after feeding GPE diets from pre-puberty.

\section{Material And Methods}

\subsection{Animals and feeding trial}


Chinese Hu sheep is famous for their high fecundity and early sexual maturity with reached puberty at 120 days of age. In this study, twenty-seven-3-month-old Hu lambs (average body weight of $(22.9 \pm 1.3$ $\mathrm{kg}$ ) were housed in individual pens $(1 \mathrm{~m} \times 1.5 \mathrm{~m})$ and randomly divided into three groups $(\mathrm{n}=9)$. Lambs in control group were fed diets without GPE, while in TAN1 and TAN2 received diets contained $0.36 \%$ and $0.72 \%$ GPE. The GPE was purchased from the Shanghai Jiaoyuan Co. Ltd. (Shanghai China), and purity quotient of GPE was up to $95 \%$,condensed tannin was $56.5 \%$. The diets (Table 1) were formulated as diet pellets with $6 \mathrm{~mm}$ in diameter.

Table 1

The content of diet

\begin{tabular}{|c|c|c|c|}
\hline Ingredient (\% of DM) & Content & Nutrient levels (\% of DM) & Content \\
\hline Barley straw & 26.00 & Metabolizable energy $\left.\left(\mathrm{MJ} \cdot \mathrm{kg}^{-1}\right) \mathrm{b}\right)$ & 12.6 \\
\hline Corn & 45.25 & Crude protein & 16.30 \\
\hline Malt root & 8.00 & Neutral detergent fiber & 35.10 \\
\hline Concentrates $^{\mathrm{a})}$ & 20.75 & Phosphorus & 0.34 \\
\hline Total & 100.00 & Calcium & 0.65 \\
\hline \multicolumn{4}{|c|}{$\begin{array}{l}\text { a) The Concentrate is composed of soybean meal, cotton seed meal, corn gluten meal, secondary } \\
\text { powder, powder, vitamin and mineral premix, and provided the mineral premix (mg) and vitamin(IU) } \\
\text { per kg of diets: Fe,70; Zn, } 41 ; \mathrm{Cu}, 8 ; \mathrm{I}, 0.7 ; \mathrm{Mn}, 24 ; \mathrm{Se}, 0.3 ; \mathrm{Co}, 0.3 ; \mathrm{VA}, 2500 ; \mathrm{VE}, 23 \text {. }\end{array}$} \\
\hline
\end{tabular}

The entire experimental period lasted for 81 days with the adaptation period from D0 to D20 and normal commencing trial period from D21 to D80. All rams were fed thrice a day at 8:00, 14:00 and 19:00 under free food intake and with libitum access to fresh water and multi-mutrient blocks. The daily feed intake was calculated from D21 to D30 and D71 to D80. All rams were weighted at the D21 and D80.

The trial was performed at Minqin Zhongtian Sheep Industry Co., Ltd. (Minqin, China) from August to November.

This study was conducted in strict accordance with the recommendations from the Guide for the Animal Care and Use Committee of Lanzhou University.

No lamb was harmed during the feeding trial.

\subsection{Sample collection}

Peripheral blood samples were collected at D81 and centrifuged at $1000 \mathrm{~g}$ at $4^{\circ} \mathrm{C}$ for $30 \mathrm{~min}$ to isolated serum. All lambs except the heaviest and lightest in each group were humanely slaughtered by a licensed slaughter man as previously described at the Minqin Zhongtian Sheep Industry Co. Ltd[13]. Their body, testis, epididymis weight and testis volume was evaluated as previously described[13]. After that, tissues 
from left testis without tunica albuginea were collected and stored using nitrogen and $10 \%$ formalin, respectively.

\subsection{RNA isolation and cDNA synthesis}

Total RNA was isolated using TRIzol reagent in accordance with the manufacturer's instruction. The RNA purity and integrity were detected by using NanoDrop 2000 spectrophotometer (Thermo Fisher, Waltham, USA) and formaldehyde denaturing gel electrophoresis. The total RNA $(2.5 \mu \mathrm{g})$ with A260/280 ratio between 1.8 to 2.0 and A260/230 ratio higher than 2.0 was reverse-transcribed to cDNA by using TransScript one-step gDNA removal and cDNA synthesis super-mix kit (TransGen Biotech, Beijing, China) at $42^{\circ} \mathrm{C}$ for $15 \mathrm{~min}$ and $85^{\circ} \mathrm{C}$ for $5 \mathrm{~s}$ following the manufacturer's instructions. The cDNA was diluted 1:10 with nuclease-free water and used for quantitative gene expression.

\subsection{Quantitative real-time PCR analysis}

The relative expression levels of anti-oxidative related genes, proliferation related genes and steroidogenesis related genes (Table 2) were detected by using transStart tip green qPCR super-mix (TransGen Biotech, Beijing, China) with Bio-Rad CFX96 real-time system (Bio-Rad, CA, USA) according to the previously reported[13]. The gene-specific primers used are shown in Table 2. The relative expression value of the target genes was normalized to the expression levels of hypoxanthine phosphoribosy transfer 1 (HPRT1), ribosomal protein S18 (RPS18) and ribosomal protein lateral stalk subunit P2 (RPLP2). The mRNA levels were expressed as the relative fold change $\left(2^{-\triangle \Delta C q}\right)$. 
Table 2

Primers sequences for analysed by quantitative RT-PCR experiments

\begin{tabular}{|c|c|}
\hline Gene & Primer sequence \\
\hline & $5^{\prime}-3^{\prime}$ \\
\hline GPX3 & F: ctggtcattctgggettcc \\
\hline XM_015096153.1 & R: ctgctctttctccccgttc \\
\hline GSTA1 & F: gaaaaagacgccaagctgac \\
\hline XM_012100854.2 & R: aggctagggtccagctcttc \\
\hline LHR & F: aatggcggtcctcatcttca \\
\hline NM_001278566.1 & R: atacagaaacggattggcgc \\
\hline FSHR & F: ccacaccaaaagccagtacc \\
\hline XM_015093783.1 & R: gctcaccttcatgtagctgc \\
\hline Cu-ZnSOD & F: ggagacctgggcaatgtgaa \\
\hline XM_004012626.3 & R: cctccagcgtttccagtctt \\
\hline StAR & F: cccagctgcgtggatttatc \\
\hline NM_001009243.1 & R: ctctccttcttccagecctc \\
\hline $3 \beta \mathrm{HSD}$ & F: gaatcggcatggttctgtcc \\
\hline XM_012183658.1 & R: ccgtagatgtacatgggcct \\
\hline P450scc & F: cagggctccggaaagtttgt \\
\hline NM_001093789.1 & R: acggtacagttctggaggga \\
\hline P450arom & F: gcatggcaagctctccttct \\
\hline XM_001123000.1 & R: caccacgtttctcggcaaaa \\
\hline PCNA & F: ttggtgcagctaacccttcg \\
\hline XM_004014340.2 & R: gtccgcattatcttcagccct \\
\hline PPARY & F: acggcggcttctacaccgact \\
\hline XM_015093026.1 & R: tgccgcttgacccactcgt \\
\hline
\end{tabular}

$3 \beta H S D=3 \beta$-hydroxysteroid dehydrogenase; Cu-ZnSOD = copper-zinc superoxide dismutase; ELOVL2 = elongation of very long chain fatty acids protein 2; FADS2 = fatty acid desaturase 2; FSHR = folliclestimulating hormone receptor; GPX3 = glutathione peroxidase 3; GSTA1 = glutathione S-transferase A1; HPRT1 = hypoxanthine phosphoribosyl transferase 1; LHR = luteinizing hormone receptor; P450scc = cholesterol side-chain cleavage enzyme, p450arom = cytochrome aromatase P450; PCNA $=$ proliferating cell nuclear antigen; PPARY $=$ peroxisome proliferators-activated receptors $\gamma ;$ RPLP2 = ribosomal protein lateral stalk subunit P2; RPS18 = ribosomal protein S18; StAR = steroid acute regulatory protein. 


\begin{tabular}{|c|c|}
\hline \multirow[t]{2}{*}{ Gene } & Primer sequence \\
\hline & $5^{\prime}-3^{\prime}$ \\
\hline FADS2 & F: acccattgagtacggcaaga \\
\hline XM_015103138.1 & R: gtacaaagggatgagcagcg \\
\hline ELVOL2 & F: acagacctgctctttccctc \\
\hline XM_015093202.1 & R: tgtagcctccttcccaactg \\
\hline HPRT1 & F: cgactggctcgagatgtgat \\
\hline XM_015105023.2 & R: tcacctgttgactggtcgtt \\
\hline RPS18 & F:cactgaggacgaggtggaac \\
\hline XM_004018745.3 & R:ctgtgggeccgaatcttctt \\
\hline RPLP2 & F:agcgccaaggacatcaaaaag \\
\hline XM_004023349.4 & R:tggccagcttgccgatac \\
\hline \multicolumn{2}{|c|}{ 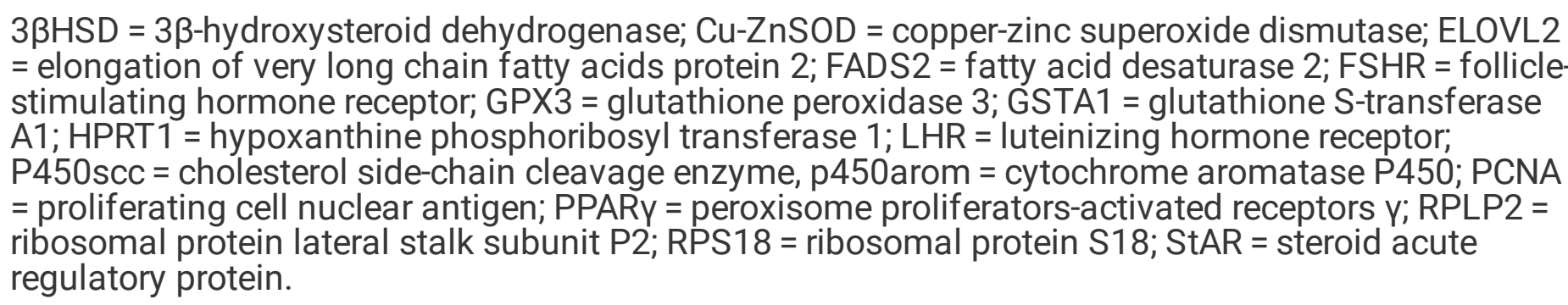 } \\
\hline
\end{tabular}

\subsection{Western blotting analysis}

Total protein was isolated from testis using IP cells lysis buffer. The protein concentrations were estimated by BCA. Approximately $30 \mu \mathrm{g}$ total protein was separated by SDS-PAGE on a polyacrylamide gel and then transferred onto PVDF membranes with a pore size of $0.45 \mu \mathrm{m}$. Then, membranes were blocked $2 \mathrm{~h}$ at room temperature with 5\% fat-free milk, and incubated with primary antibodies [1:200 for Zn-CuSOD (CUSABIO, Wuhan, Chian) and 3ßHSD (Bioss, Beijing, China), 1:600 for FSHR, StAR (Bioss, Beijing, China) and PCNA (Abcam, Cambridge, UK), and 1:1000 for $\beta$ Actin (Abcam, Cambridge, UK)] overnight at $4^{\circ} \mathrm{C}$. After that, membranes were washed 3 times with PBST, and incubated with HRPconjugated goat anti-rabbit secondary antibody antibody (Abcam, Cambridge, UK) at a 1:5000 dilution for $2 \mathrm{~h}$ at room temperature. After incubated, the membranes were washed 3 times and images were captured by Bio-Rad chemiluminescent image systems (Bio-Rad, CA, USA) using beyoECL plus kit (Thermo Fisher, Waltham, USA).

\subsection{Testosterone, estradiol and LH levels}

LH in the blood serum was detecting using Sheep Luteinizing Hormone (LH) ELISA Kit (CUSABIO, Wuhan, China) with detection reange $2-75 \mathrm{mlU} / \mathrm{mL}$, and intra-assay and inter-assay coefficient of variations (CVs) were both $\leq 15 \%$, according to the instruction. Testosterone and estradiol were detected by using 
an automated chemiluminescent microparticle immunoassay with Architect 2nd generation testosterone kit and Architect estradiol assay kit on Architect i4000SR system (Abbott Park, USA) as we previously mentioned[13].

\subsection{Lipid extraction and fatty acid analysis}

Testis lipids were extracted from $0.5 \mathrm{~g}$ of tissue by homogenization in chloroform/methanol (2:1, v/v). Trans-methylation of these samples was performed using the Metcalf method [14]. Fatty acids methyl esters were separated and quantified by TRACE 1300 gas chromatograph (Thermo Fisher, Waltham, USA) equipped with a flame ionization detector and a $100 \mathrm{~m} \times 0.25 \mathrm{~mm} \times 0.25 \mu \mathrm{m}$ (HP-88, Agilent Technologies) fused silica capillary column. Nitrogen was used as carrier gas and temperature programming was from $50^{\circ} \mathrm{C}$ to $175^{\circ} \mathrm{C}$ at $13^{\circ} \mathrm{C} / \mathrm{min}$, and held there for $27 \mathrm{~min}$, and then temperatureprogrammed at $3^{\circ} \mathrm{C} / \mathrm{min}$ to $215^{\circ} \mathrm{C}$, and held there for $27 \mathrm{~min}$. The injector and detector temperatures were set at $240^{\circ} \mathrm{C}$. Peak identification was based on the elution profile of known FAME chromatographic standards (fatty acid methyl esters, C4-C24, Nuchek Prep, Elysian, MN, USA) and previously reported [15, 16]. Relative quantification was normalized with the sum of all the detected species and shown as a percentage of total species[17].

\subsection{Biochemical assays}

Testicular tissues were weighted and homogenized in ice-cold PBS to create a 1:10 suspension with repeated freezing and thawing. After centrifuged at $10000 \mathrm{~g}$ for $5 \mathrm{~min}$ at $4^{\circ} \mathrm{C}$, the supernatants concentrations were determined using BCA method.

Total antioxidant capacity (T-AOC) assay kit, superoxide dismutase (SOD) assay kit, total cholesterol assay kit, total triglyceride assay kit and non-esterified free fatty acids (NEFAs) assay kit (Nanjing Jiancheng, Nanjing, China) were used to measuring T-AOC, SOD, cholesterol, triglyceride and NEFAs on Epoch Microplate Reader (Bio-Tek Instruments, Winooski, VT, USA) according to the manufacturer's protocols.

The biochemical concentrations were normalized with total protein in testicular tissues suspension.

\subsection{Testicular histology}

Testicular histology was analysed as previously described [13]. Briefly, testicular tissues ( $5 \mathrm{~mm} \times 5 \mathrm{~mm} \times 5$ $\mathrm{mm}$ ) were fixed, dehydrated and embedded. Then sectioned at $5 \mu \mathrm{m}$ thicknesses, and stained with hematoxylin and eosin (H\&E). Histological evaluation was performed by light microscopy and images were captured using the Scopeimage 9.0 software (Ningbo yongxin, Ningbo, China). Diameter of seminiferous tubules and the number of Sertoli cells were analysed. For each tissue, 6 to 10 seminiferous tubules were elevated.

\subsection{Statistical analysis}

The experimental results were presented as the group mean \pm standard error of mean. The data was evaluated with SPSS program, version 13.0 (SPSS, Chicago, USA). Normal parameters were analysed by 
One-sample Kolmogorov-Smirnov test. Homogeneity of variances were analysed by Leven's test.

Significant differences were analysed by one-way ANOVA and Welch (unequal variances). Multiple comparisons between groups were compared with LSD and Dunnett T3 (unequal variances). $P$ values < 0.05 was considered statistically significant.

\section{Results}

\subsection{Effect of GPE on testicular development and histology}

No significant differences in the dry matter intake, body weight, average daily gain, scrotal circumference and testis index were observed among groups after consuming GPE $(P>0.05)$. Compared with the control group, supplementation with $0.72 \%$ GPE significantly increased the testis weight, $0.36 \%$ GPE significantly increased testis weight, testis volume, and epididymis weight $(P<0.05)$ (Table 3). Histological studies showed extensive changes evident by germinal epithelium in the control and GPE treatment groups. The thickness of cellular wall of tubules and spermatogenic cells in TAN1 and TAN2 groups were significantly increased with four or more layers of different stages of germ cells in their seminiferous epithelium. The lumen of seminiferous tubules became larger with diameter $164.49 \pm 5.37 \mu \mathrm{m}$ in TAN1, $146.56 \pm 4.53 \mu \mathrm{m}$ in TAN2 and $109.3 \pm 4.56 \mu \mathrm{m}$ in the control group $(P<0.05)$. The elongated spermatozoids were also observed in the lumina of seminiferous after GPE treatment (Fig. 1). The number of Sertoli cells per seminiferous tubule cross-section was also increased after feeding GPE (14.10 \pm 0.57 in TAN1 and 13.60 \pm 0.42 in TAN2) compared with the control group $(10.56 \pm 0.44, P<0.05)$. 
Table 3

Effect of GPE on the growth performance and testis development.

\begin{tabular}{|c|c|c|c|c|}
\hline Item & Control & TAN1 & TAN2 & P-value \\
\hline Initial weight, $\mathrm{kg}$ & $22.76 \pm 0.33$ & $22.72 \pm 0.47$ & $22.93 \pm 0.32$ & 0.92 \\
\hline Body weight, $\mathrm{kg}$ & $37.19 \pm 0.49$ & $39.11 \pm 0.72$ & $38.73 \pm 0.51$ & 0.07 \\
\hline$A D G, g$ & $242.58 \pm 9.21$ & $259.72 \pm 7.58$ & $261.24 \pm 10.73$ & 0.31 \\
\hline $\mathrm{DMI}_{\mathrm{D} 21-\mathrm{D} 30}, \mathrm{~kg} /$ day & $1.27 \pm 0.08$ & $1.31 \pm 0.05$ & $1.38 \pm 0.04$ & 0.38 \\
\hline $\mathrm{DMI}_{\mathrm{D} 71-\mathrm{D} 80}, \mathrm{~kg} /$ day & $1.73 \pm 0.06$ & $1.78 \pm 0.05$ & $1.82 \pm 0.12$ & 0.76 \\
\hline Scrotal circumference, $\mathrm{cm}$ & $18.20 \pm 1.61$ & $23.20 \pm 1.98$ & $24.00 \pm 1.99$ & 0.09 \\
\hline Testis weight, $\mathrm{g}$ & $145.32 \pm 25.88$ & $291.85 \pm 50.79 *$ & $276.06 \pm 47.93^{*}$ & 0.05 \\
\hline Testis volume, $\mathrm{mL}$ & $154.14 \pm 28.35$ & $322.86 \pm 60.16^{\star}$ & $297.57 \pm 53.20$ & 0.05 \\
\hline Testis index, $\mathrm{g} / \mathrm{kg}$ & $3.92 \pm 0.71$ & $7.51 \pm 1.31$ & $7.07 \pm 1.19$ & 0.07 \\
\hline Epididymis weight, $\mathrm{g}$ & $35.43 \pm 2.23$ & $47.03 \pm 3.23^{\star \star}$ & $42.60 \pm 2.17$ & 0.02 \\
\hline Seminiferous tubule diameter, $\mu \mathrm{m}$ & $109.3 \pm 4.56$ & $164.49 \pm 5.37 *$ & $146.56 \pm 4.53^{\star}$ & $<0.01$ \\
\hline No. of Sertoli cells & $10.56 \pm 0.44$ & $14.10 \pm 0.57 *$ & $13.60 \pm 0.42^{\star}$ & $<0.01$ \\
\hline
\end{tabular}

\subsection{Effect of GPE on testis T-AOC, SOD, NEFAs TG and cholesterol levels}

Antioxidant status of testis was markedly increased after consuming GPE. Compared with control group (314.23 $\pm 18.64 \mathrm{U} / \mathrm{mg}$ prot), consuming $0.36 \%$ (505.22 $\pm 63.47 \mathrm{U} / \mathrm{mg}$ prot, $P<0.05)$ and $0.72 \%$ (587.88 \pm $55.94 \mathrm{U} / \mathrm{mg}$ prot, $P<0.01)$ GPE significantly increased the SOD activity in testis tissue. The T-AOC in TAN1 and TAN2 (202.15 \pm 34.19 and $189.57 \pm 18.95 \mathrm{U} / \mathrm{g}$ prot) was significantly higher than the control group (98.23 $\pm 18.99 \mathrm{U} / \mathrm{g}$ prot, $P<0.05)$. The NEFAs levels were also increased in TAN1 $(205.15 \pm 14.51$ $\mathrm{mmol} / \mathrm{kg} \mathrm{prot})$ and TAN2 $(250.06 \pm 33.82 \mathrm{mmol} / \mathrm{kg}$ prot) groups compared with the control $(158.36 \pm$ $26.32 \mathrm{mmol} / \mathrm{kg}$ prot, $P=0.08)$. However, the testicular total cholesterol concentration was downregulated after consuming compared with the control group ( $3.89 \pm 0.57 \mathrm{mmol} / \mathrm{kg}$ prot in TNA1, $4.21 \pm 1.04$ $\mathrm{mmol} / \mathrm{kg}$ prot in TAN2 and $7.20 \pm 1.46 \mathrm{mmol} / \mathrm{kg}$ prot in the control, $P=0.09)$. There was no difference in testicular total triglyceride concentration among three groups (Table 4 ). 
Table 4

Effect of GPE on SOD, T-AOC, cholesterol and free fatty acid in the testis

\begin{tabular}{|lllll|}
\hline Item & Control & TAN1 & TAN2 & P-value \\
\hline TG, mmol/kg prot & $27.94 \pm 5.79$ & $21.29 \pm 2.71$ & $26.86 \pm 3.40$ & 0.50 \\
\hline T-CHO, mmol/kg prot & $7.20 \pm 1.46$ & $3.89 \pm 0.57$ & $4.21 \pm 1.04$ & 0.09 \\
\hline T-AOC, U/g prot & $98.23 \pm 18.99$ & $202.15 \pm 34.19 \star \star$ & $189.57 \pm 18.95^{\star}$ & 0.02 \\
\hline SOD, U/mg prot & $314.23 \pm 18.64$ & $505.22 \pm 63.47 \star$ & $587.88 \pm 55.94 \star \star$ & $<0.01$ \\
\hline NEFAs, mmol/kg prot & $158.36 \pm 26.32$ & $205.15 \pm 14.51$ & $250.06 \pm 33.82$ & 0.08 \\
\hline $\begin{array}{l}\text { NEFAs = nonesterified free fatty acids; T-AOC = total anti-oxidation capacity; TG = triglyceride; } \text { T-CHO = } \\
\text { total cholesterol; }\end{array}$ & & & \\
\hline
\end{tabular}

\subsection{Effect of GPE on hormone levels}

The average concentrations of plasma T, E2 and LH were not affected after GPE treatment (Table 5).

Table 5

Effect of dietary GPE in the LH, Testosterone and Estradiol concentration in the peripheral blood

\begin{tabular}{|lllll|}
\hline & Control & TAN1 & TAN2 & P-value \\
\hline LH(mlU/mL $)$ & $0.34 \pm 0.09$ & $0.16 \pm 0.04$ & $0.21 \pm 0.06$ & 0.19 \\
\hline Testosterone $(\mathrm{ng} / \mathrm{mL})$ & $0.56 \pm 0.09$ & $0.65 \pm 0.16$ & $0.37 \pm 0.06$ & 0.24 \\
\hline Estradiol $(\mathrm{pg} / \mathrm{mL})$ & $15.00 \pm 0.76$ & $16.00 \pm 1.15$ & $14.86 \pm 1.03$ & 0.68 \\
\hline Note: Values were shown as means \pm SEM. & & \\
\hline
\end{tabular}


Table 6

Effect of GPE on fatty acids profiles in the testis

\begin{tabular}{|c|c|c|c|c|c|}
\hline No. & Fatty acids & Control & TAN1 & TAN2 & P-value \\
\hline 1 & C16:0 & $19.36 \pm 1.65$ & $19.93 \pm 1.08$ & $20.84 \pm 0.66$ & 0.64 \\
\hline 2 & C15:1 & $1.38 \pm 0.07$ & $1.53 \pm 0.25$ & $2.46 \pm 0.19 *$ & 0.01 \\
\hline 3 & C16:1 & $0.4 \pm 0.05$ & $0.41 \pm 0.02$ & $0.38 \pm 0.03$ & 0.74 \\
\hline 4 & C17:0 & $0.31 \pm 0.02$ & $0.35 \pm 0.02$ & $0.34 \pm 0.01$ & 0.22 \\
\hline 5 & $\mathrm{C} 17: 1$ & $0.12 \pm 0.01$ & $0.12 \pm 0.01$ & $0.1 \pm 0.01$ & 0.54 \\
\hline 6 & C18:0 & $8.54 \pm 0.42$ & $7.87 \pm 0.25$ & $7.13 \pm 0.12^{\star}$ & 0.01 \\
\hline 7 & $\mathrm{C} 18: 1 \mathrm{n}$ & $43.22 \pm 4.53$ & $41.7 \pm 1.01$ & $41.71 \pm 2.22$ & 0.96 \\
\hline 8 & C18:2n6 & $1.91 \pm 0.14$ & $1.81 \pm 0.15$ & $1.82 \pm 0.16$ & 0.9 \\
\hline 9 & C18:3n3 & $0.13 \pm 0.01$ & $0.11 \pm 0.01$ & $0.11 \pm 0.02$ & 0.67 \\
\hline 10 & $\mathrm{C} 20: 2 \mathrm{n} 6$ & $0.14 \pm 0.01$ & $0.09 \pm 0.02$ & $0.13 \pm 0.02$ & 0.34 \\
\hline 11 & $\mathrm{C} 20: 3 \mathrm{n} 3$ & $0.24 \pm 0.08$ & $0.51 \pm 0.11$ & $0.27 \pm 0.07$ & 0.12 \\
\hline 12 & $\mathrm{C} 20: 3 \mathrm{n} 6$ & $1.21 \pm 0.33$ & $1.09 \pm 0.17$ & $1.28 \pm 0.16$ & 0.77 \\
\hline 13 & $\mathrm{C} 20: 4 \mathrm{n} 6$ & $9.42 \pm 1.01$ & $10 \pm 0.43$ & $8.6 \pm 0.51$ & 0.25 \\
\hline 14 & $\mathrm{C} 20: 5 \mathrm{n} 3$ & $0.09 \pm 0.04$ & $0.15 \pm 0.03$ & $0.12 \pm 0.02$ & 0.38 \\
\hline 15 & $\mathrm{C} 24: 1$ & $1.39 \pm 0.36$ & $1.37 \pm 0.12$ & $1.34 \pm 0.07$ & 0.97 \\
\hline 16 & $\mathrm{C} 22: 4 \mathrm{n} 6$ & $6.3 \pm 2.13$ & $6.86 \pm 0.19$ & $6.05 \pm 0.84$ & 0.70 \\
\hline 17 & $\mathrm{C} 22: 5 \mathrm{n} 3$ & $4.06 \pm 0.35$ & $3.06 \pm 0.63$ & $2.38 \pm 0.28^{*}$ & 0.03 \\
\hline 18 & $\mathrm{C} 22: 6 \mathrm{n} 3$ & $1.79 \pm 0.32$ & $3.03 \pm 0.92$ & $4.93 \pm 0.36^{*}$ & 0.03 \\
\hline 19 & SFA & $28.21 \pm 1.22$ & $28.16 \pm 0.99$ & $28.31 \pm 0.67$ & 0.99 \\
\hline 20 & MUFA & $46.51 \pm 4.24$ & $45.13 \pm 0.91$ & $45.99 \pm 2.31$ & 0.92 \\
\hline 21 & PUFA & $25.28 \pm 3.21$ & $26.71 \pm 0.69$ & $25.7 \pm 1.69$ & 0.84 \\
\hline 22 & $\mathrm{~N}-3$ & $6.3 \pm 0.07$ & $6.86 \pm 1.06$ & $7.82 \pm 0.2^{\star}$ & $<0.01$ \\
\hline 23 & $\mathrm{~N}-6$ & $18.98 \pm 3.25$ & $19.84 \pm 0.42$ & $17.88 \pm 1.6$ & 0.67 \\
\hline 24 & $\mathrm{~N}-3 / \mathrm{N}-6$ & $0.36 \pm 0.08$ & $0.35 \pm 0.06$ & $0.45 \pm 0.04$ & 0.39 \\
\hline
\end{tabular}

Note: Values were shown as mean \pm SEM. ${ }^{*} P<0.05$, compared with the control group. 
Real-time qPCR analysis results (Fig. 2) indicated that Cu-ZnSOD, P450scc, P450arom, FSHR, FADS2, ELOVL2 and PCNA mRNA in TAN1 and TAN2 groups were significantly up-regulated. GSTA1, GPX3 and StAR in TAN1 were also stimulated by GPE $(P<0.05)$. Western blotting result was in agreement with the mRNA levels. Consuming GPE significantly increased Cu-ZnSOD, FSHR PCNA and StAR protein expression levels $\square P<0.05 \rrbracket$ (Fig. 3).

\subsection{Effect of GPE on testis fatty acid.}

Fatty acids in lamb testes contained approximately $28 \%$ saturated fatty acids, $46 \%$ monounsaturated fatty acids, and nearly $26 \%$ polyunsaturated fatty acids. $18 \%$ of n- 6 fatty acids and $7 \%$ of n-3 fatty acids. As observed for the fatty acids profile, GPE treatment altered the fatty acids composition in testes. Supplementation 0.72\% GPE significantly increased C15:1, C22:6n3 and total n-3 fatty acids in comparison to the control, but decreased C22:5n3 $(P<0.05)$. C20:3n3 in TAN1 group was also much more than in the control group.

\section{Discussion}

The testes, as the endocrine glands that are part of the male reproductive system, and their main functions are to secrete androgens and produce sperm. There is a large amount of ROS produced during spermatogenesis. ROS and lipid peroxidation reactions play an important role in the metabolism. However, it could cause metabolic dysfunction once the ROS balance is disrupted. ROS could attack PUFA in the cell membrane, disrupted the structure of the cell membrane and induced various diseases [18]. Oxidase such as SOD and catalase play an important role in the antioxidant defence system. With the increase of ecological and environmental protection efforts, China's sheep industry is developing towards house feeding, but captive raising ROS levels of testicular tissue is not conducive to ram sperm production [11]. Therefore, improving the antioxidant capacity of male animals and protecting the structural and functional integrity of the testes are essential for improving the quality of male semen. Grape residue contains tannic acid and has strong antioxidant capacity. Grape seed tannin can capture free radicals in the body and inhibit the production of free radicals [19]. It has functions of bacteriostasis, improving rumen fermentation of ruminants and intestinal microbial environment, lowering blood lipids, etc., protecting the health of the body, and is a valuable food antioxidant [5-9].

T-AOC can comprehensively evaluate the strength of the antioxidant defense system in animals and effectively translate the compensatory capacity of the body to external stimuli. The supplementation of GPE in the present study did not affect the body weight, the average daily gain,but increased T-AOC, SOD concentration in testis, up-regulated GPX3 and Cu-ZnSOD expression. These results were consisted with Zhao $\mathrm{J}$ et al[11]. This could enhance antioxidant capacity in testis, and prevent oxidant stress happening. Polyphenols also regulate expression of genes related to lipogenesis and lipocatabolic in liver [20]. Related research revealed that tannin could reduce blood lipids and blood sugar[21]. Lipid in testis contains high a ratio of PUFA. The PUFA composition and profile is associated with testis development and spermatogenesis[22]. Fatty acid from liposynthesis and absorb from food could be metabolism to 
SFA, MUFA and PUFA through fatty acid synthetase, desaturase and elongase. These enzymes could be regulated by metabolite, hormone, transcription factor or competitive substances of rate-limiting enzyme[13]. The composition of PUFA is vulnerable to the diet. In the present study, GPE stimulated FADS2 and ELOVL2 expression, and contribute to EPA and DHA synthesis. Previously studies indicated that decreasing of DHA in sperm membrane was associated with decreasing fertility [23, 24]. Fortunately, the concentration of DHA in this study was upregulated after consuming GPE. DHA in testicular may contribute to spermatogenesis and sperm quality [24]. The sperm motility, membrane fluidity is associated with n-3 PUFA in sperm [23-25]. PUFA in the sperm head and tile affects the sperm capacitation and interaction between sperm and uterine surface environment [26].

StAR activation is the first stage in steroid hormone synthesis, which modulates the translocation of cholesterol from outer to inner mitochondrial membrane. In the present study, GPE significantly upregulated the expression of StAR, P540scc and P450arom, and stimulate testis development with testis weight, diameter of seminiferous tubule and number of Sertoli cells increased. The sperm production was determined by adult testis size and the number of Sertoli cells [27]. In this study, GPE significantly increased testis and epididymis weight, stimulated spermatogenesis with increased number of Sertoli cells, and up-regulated PCNA mRNA expression in testis. However, the GPE did not increase the levels of $\mathrm{LH}$, testosterone and estradiol in plasma in the present study. These results may be due to the discrepancy between the hormone levels in plasma and genes expression induced by the fatty acid profile changed by GPE. Seminar result was also reported in pig feeding Soybean oil and hydrogenated soybean oil from aged one-month to 18-month. Soybean oil inhibited testosterone and estradiol, however, it increased sterogenesis related genes expression [28].

\section{Conclusions}

Inclusion, supplementation with GPE during early testis development stage could increase anti-oxidant ability in testis, change the testicular fatty acid profile with increasing DHA and stimulate testis development and spermatogenesis.

\section{Abbreviations}

Grape seed tannin extract: GPE; Nonesterified free fatty acids: NEFAs; Total anti-oxidation capacity: T-

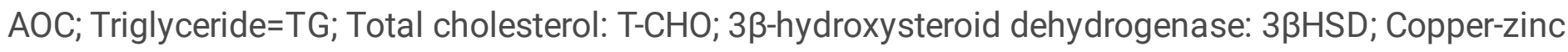
superoxide dismutase: Cu-ZnSOD; Elongation of very long chain fatty acids protein 2: ELOVL2; Fatty acid desaturase 2: FADS2; Follicle-stimulating hormone receptor: FSHR; Glutathione peroxidase 3: GPX3; Glutathione S-transferase A1: GSTA1; Hypoxanthine phosphoribosyl transferase 1: HPRT1; Luteinizing hormone receptor: LHR; Cholesterol side-chain cleavage enzyme: P450scc , Cytochrome aromatase P450: P450arom; Proliferating cell nuclear antigen: PCNA; Peroxisome proliferators-activated receptors $\gamma$ : PPARy; Ribosomal protein lateral stalk subunit P2: RPLP2; Ribosomal protein S18: RPS18; Steroid acute regulatory protein: StAR 


\section{Declarations}

\section{Authors' contributions}

W.H. Li and F.D. Li conceived and designed the experimental plan. R.Y. Yao, L.X. Xie, J.M. Liu and X.X. Weng were involved in experiments, analysis and data collection. W.H. Li, R.Y. Yao, J.M. Liu drafted the original manuscript. X.P. Yue made a revision of this manuscript. All authors read and approved the final manuscript.

\section{Funding}

This study was supported by the Fundamental Research Funds for the Central Universities (Izujbky-201939), the National Natural Science Foundation of China (31702112), and the China Agriculture Research System (CARS-38).

\section{Availability of data and materials}

The datasets used/or analysed during the current study are available from the corresponding author on reasonable request.

\section{Ethics approval and consent to participate}

This study was conducted in strict accordance with the recommendations from the Guide for the Animal Care and Use Committee of Lanzhou University.

\section{Consent for publication}

All of the authors have approved the final version of the manuscript and agreed with this submission to the Journal of Animal Science and Biotechnology.

\section{Competing interests}

The authors declare that they have no competing interests.

\section{References}

1. Carpenter R, O'Grady MN, O'Callaghan YC, O'Brien NM, Kerry JP. Evaluation of the antioxidant potential of grape seed and bearberry extracts in raw and cooked pork. Meat Sci. 2007;76:604-10.

2. Tseng A, Zhao Y. Effect of different drying methods and storage time on the retention of bioactive compounds and antibacterial activity of wine grape pomace (Pinot Noir and Merlot). J Food Sci. 
2012;77:H192-201.

3. Guendez R, Kallithraka S, Makris DP, Kefalas P. Determination of low molecular weight polyphenolic constituents in grape (Vitis vinifera sp.) seed extracts: Correlation with antiradical activity. Food Chem. 2005;89:1-9.

4. Rondeau P, Gambier F, Jolibert F, Brosse N. Compositions and chemical variability of grape pomaces from French vineyard. Ind Crops Prod. 2013;43:251-4.

5. Girard M, Bee G. Tannins as a potential alternative to antibiotics to prevent coliform diarrhea in weaned pigs. Animal. 2020;14:95-107.

6. Huang Q, Liu X, Zhao G, Hu T, Wang Y. Potential and challenges of tannins as an alternative to infeed antibiotics for farm animal production. Animal Nutrition. 2018;4:137-50.

7. Jagannathan V, Viswanathan P. Proanthocyanidins-Will they effectively restrain conspicuous bacterial strains devolving on urinary tract infection? J Basic Microbiol. 2018;58:567-78.

8. Vasta V, Makkar HP, Mele M, Priolo A. Ruminal biohydrogenation as affected by tannins in vitro. The British Journal of Nutrition. 2009;102:82-92.

9. Min BR, Solaiman S. Comparative aspects of plant tannins on digestive physiology, nutrition and microbial community changes in sheep and goats. Journal of Animal Physiology Animal Nutrition. 2018;102:1181-93.

10. Zhu Y, Chen Y, Ren L, Lü H, Zhao W, Yuan F, et al. Ecosystem restoration and conservation in the arid inland river basins of Northwest China: Problems and strategies. Ecol Eng. 2016;94:629-37.

11. Zhao J, Jin Y, Du M, Liu W, Ren Y, Zhang C, et al. The effect of dietary grape pomace supplementation on epididymal sperm quality and testicular antioxidant ability in ram lambs. Theriogenology. 2017;97:50-6.

12. Su L, Deng Y, Zhang Y, Li C, Zhang R, Sun Y, et al. Protective effects of grape seed procyanidin extract against nickel sulfate-induced apoptosis and oxidative stress in rat testes. Toxicol Mech Methods. 2011;21:487-94.

13. Li W, Tang D, Li F, Tian H, Yue X, Li F, et al. Supplementation with dietary linseed oil during peripuberty stimulates steroidogenesis and testis development in rams. Theriogenology. 2017;102:10-5.

14. Metcalfe LD, Schmitz AA, Pelka JR. Rapid preparation of fatty acid esters from lipids for gas chromatographic analysis. Anal Chem. 1966;38:524-35.

15. Kramer JKG, Fellner V, Dugan MER, Sauer FD, Mossoba MM, Yurawecz MP. Evaluating acid and base catalysts in the methylation of milk and rumen fatty acids with special emphasis on conjugated dienes and total trans fatty acids. Lipids. 1997;32:1219-28.

16. Aldai N, Osoro K, Barrón LJR, Nájera Al. Gas-liquid chromatographic method for analysing complex mixtures of fatty acids including conjugated linoleic acids (cis9trans 11 and trans10cis12 isomers) and long-chain ( $n-3$ or $n-6)$ polyunsaturated fatty acids: Application to the intramuscular fat of beef meat. J Chromatogr A. 2006;1110:133-9. 
17. Pang SQ, Wang GQ, Jin XQ, Sun AJ, Lin J, Diao Y. Chemical composition of the fatty oil from fructus broussonetiae and its effects on rat plasma lipids and adipose tissue. American Journal of Plant Sciences. 2016;07:446-52.

18. Dutta S, Majzoub A, Agarwal A. Oxidative stress and sperm function: A systematic review on evaluation and management. Arab Journal of Urology. 2019;17:87-97.

19. Gupta M, Dey S, Marbaniang D, Pal P, Ray S, Mazumder B. Grape seed extract: having a potential health benefits. J Food Sci Technol. 2020;57:1205-15.

20. Frémont L, Belguendouz L, Delpal S. Antioxidant activity of resveratrol and alcohol-free wine polyphenols related to LDL oxidation and polyunsaturated fatty acids. Life Sci. 1999;64:2511-21.

21. Mašek T, Starčević K. Lipogenesis and lipid peroxidation in rat testes after long-term treatment with sucrose and tannic acid in drinking water. Andrologia. 2017;49.

22. delBarco-Trillo J, Mateo R, Roldan ER. Differences in the fatty-acid composition of rodent spermatozoa are associated to levels of sperm competition. Biology Open. 2015;4:466-73.

23. Kelso KA, Cerolini S, Speake BK, Cavalchini LG, Noble RC. Effects of dietary supplementation with alpha-linolenic acid on the phospholipid fatty acid composition and quality of spermatozoa in cockerel from 24 to 72 weeks of age. J Reprod Fertil. 1997;110:53-9.

24. Zalata AA, Christophe AB, Depuydt CE, Schoonjans F, Comhaire FH. The fatty acid composition of phospholipids of spermatozoa from infertile patients. Mol Hum Reprod. 1998;4:111-8.

25. Penny PC, Noble RC, Maldjian A, Cerolini S. Potential role of lipids for the enhancement of boar fertility and fecundity. Pig News Inform. 2000;21:119-26.

26. Lenzi A, Picardo M, Gandini L, Dondero F. Lipids of the sperm plasma membrane: from polyunsaturated fatty acids considered as markers of sperm function to possible scavenger therapy. Human Reproduction Update. 1996;2:246-56.

27. Orth JM, Gunsalus GL, Lamperti AA. Evidence from Sertoli cell-depleted rats indicates that spermatid number in adults depends on numbers of Sertoli cells produced during perinatal development. Endocrinology. 1988;122:787-94.

28. Miyazawa D, Ohara N, Yamada K, Yasui Y, Kitamori K, Saito Y, et al. Dietary soybean oil, canola oil and partially-hydrogenated soybean oil affect testicular tissue and steroid hormone levels differently in the miniature pig. Food Chem Toxicol. 2020;135:110927.

\section{Figures}




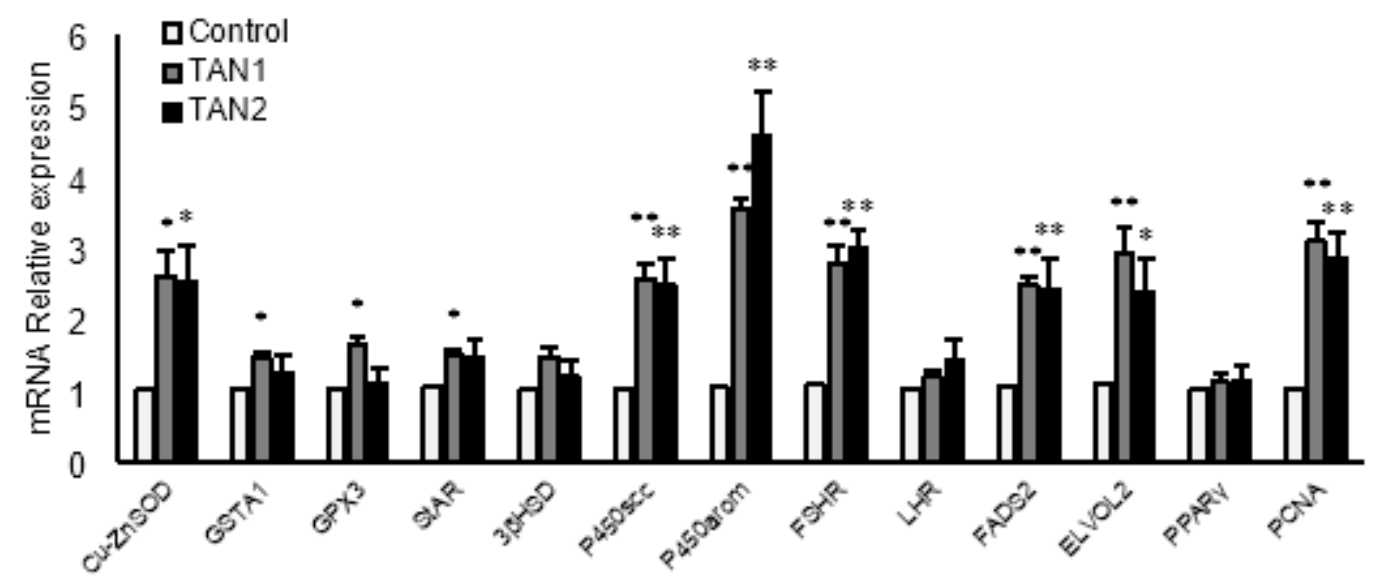

Figure 1

Effect of GPE on the mRNA levels of Cu-ZnSOD, GSTA1, StAR, 33HSD, P450scc, P450arom, FSHR, LHR, FADS2, ELVOL2, PPARY, and PCNA in lamb testes. The relative expression levels of Cu-ZnSOD (copperzinc superoxide dismutase), P450scc (cholesterol side-chain cleavage enzyme), P450arom (cytochrome aromatase P450), FSHR (follicle-stimulating hormone receptor), FADS2 (fatty acid desaturase 2), ELOVL2 (elongation of very long chain fatty acids protein 2) and PCNA (proliferating cell nuclear antigen) genes were significantly upregulated in TAN1 and TAN2 groups. The relative expression of GSTA1 (glutathione S-transferase A1), GPX3 (glutathione peroxidase3) and StAR (steroid acute regulatory protein) genes were also significantly upregulated in TAN1 group. Values were shown as means $\pm \mathrm{SEM}$. ${ }^{*} \mathrm{P}<0.05$ and ${ }^{* *} \mathrm{P}<$ 0.01 compared with the control group.

A

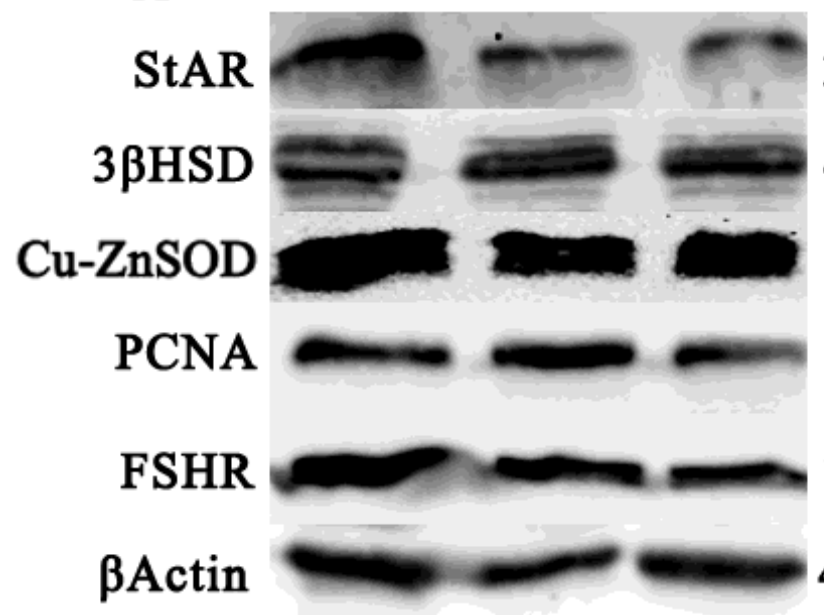

TAN1 TAN2 Control
B
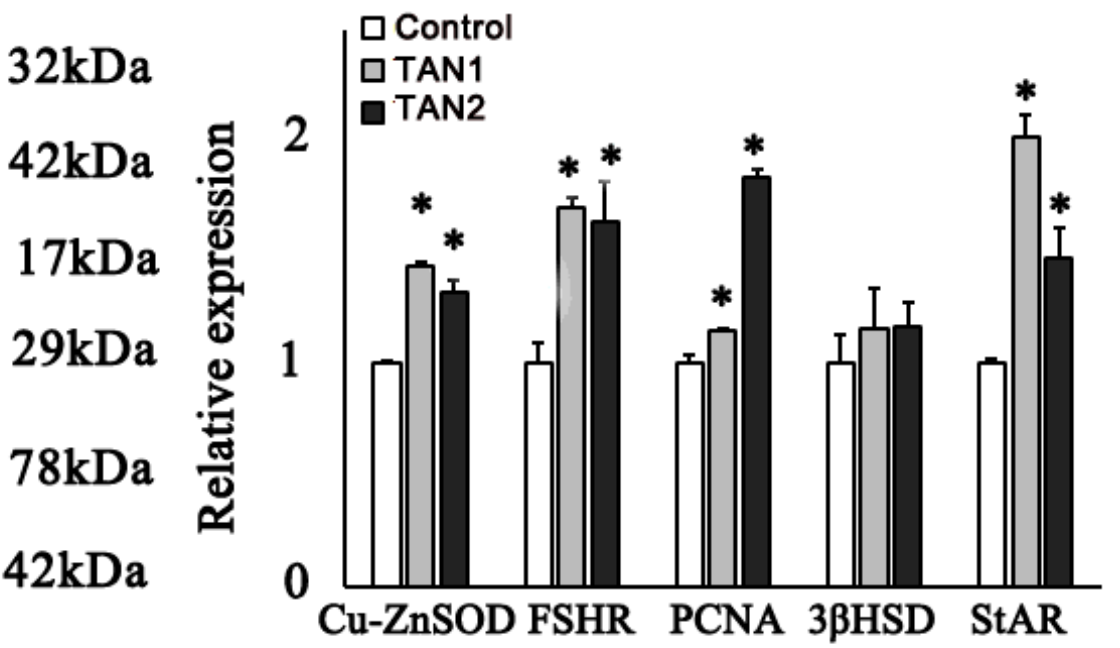

Figure 2

Effect of GPE on the protein levels of Cu-ZnSOD, FSHR, 3Bhsd, PCNA and StAR in lamb testes. The

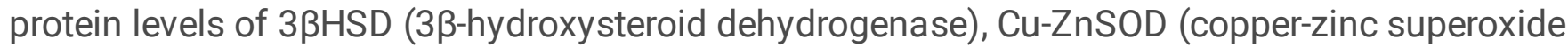
dismutase), FSHR (follicle-stimulating hormone receptor), PCNA (proliferating cell nuclear antigen) StAR 
(steroid acute regulatory protein) were significantly upregulated in TAN group. Values were shown as means \pm SEM. ${ }^{*} \mathrm{P}<0.05$ compared with the control group.
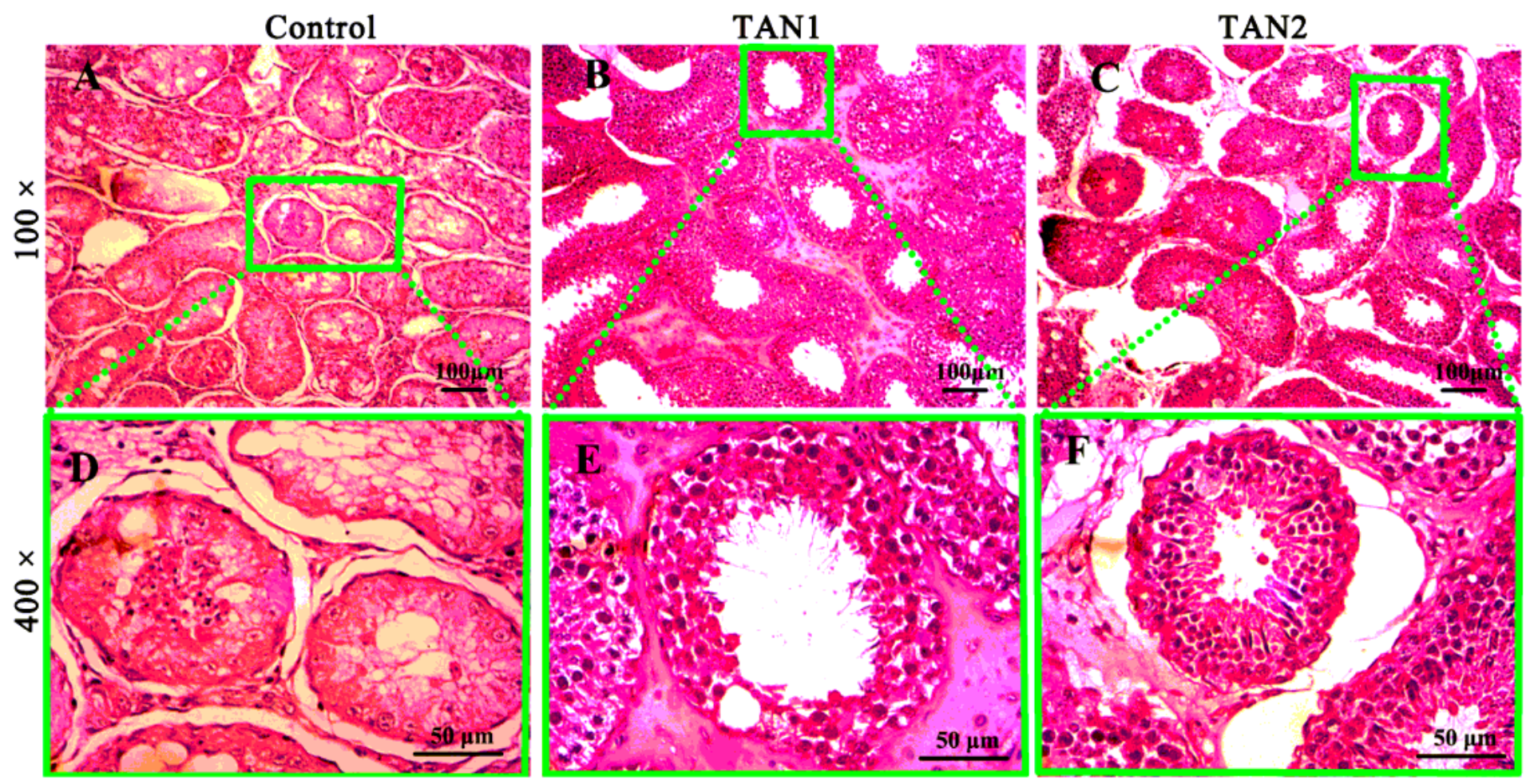

\section{Figure 3}

Histological images of testes from control and GPE groups. Hematoxylin and eosin (H\&E) staining, $100 \times$ (Green row: multiple changes were presented in a further magnification $(400 \times)$ of the green bordered box.). Testes from the GPE groups showed a compact and regular arrangement of germ cells and elongated spermatozoids in their seminiferous epithelium. 